\title{
Les îles britanniques et la révolution française
}

\section{Harry T. Dickinson et Pascal Dupuy}

\section{(2) OpenEdition}

\section{Journals}

Édition électronique

URL : https://journals.openedition.org/ahrf/1886

DOI : 10.4000/ahrf.1886

ISSN : 1952-403X

Éditeur :

Armand Colin, Société des études robespierristes

Édition imprimée

Date de publication : 1 décembre 2005

Pagination : 1-2

ISSN : 0003-4436

Référence électronique

Harry T. Dickinson et Pascal Dupuy, «Les îles britanniques et la révolution française », Annales

historiques de la Révolution française [En ligne], 342 I octobre-décembre 2005, mis en ligne le 04 mai 2006, consulté le 23 avril 2022. URL : http://journals.openedition.org/ahrf/1886 ; DOI : https://doi.org/ 10.4000/ahrf.1886

Ce document a été généré automatiquement le 23 avril 2022

Tous droits réservés 


\title{
Les îles britanniques et la révolution française
}

\author{
Harry T. Dickinson et Pascal Dupuy
}

1 Observés deux cents ans après leur déroulement, les événements de l'année 1805 auraient pu faire l'objet d'une commémoration dominée par un comparatisme soulignant les réalités qui structuraient différemment la France et le Royaume (récemment) Uni (1800). En effet, l'évocation d'Austerlitz ou de Trafalgar pourrait servir à représenter les rapports de force et les ambitions - identiques, similaires ou différentes, quoique opposées -, qui travaillaient les deux États alors les plus puissants d'Europe. Mais, plus qu'une réponse conjoncturelle à un anniversaire, aussi riche d'événements marquants soit-il, nous avons voulu donner principalement la place ici à l'évocation des études produites dans le monde anglo-saxon sur les relations et les rapports complexes qu'ont entretenu, entre 1789 et 1815, la France et les îles britanniques. Dans de nombreux domaines, mais avant tout dans celui de l'histoire politique et culturelle, souvent d'ailleurs sous l'impulsion de Harry T. Dickinson, l'un des deux rédacteurs de cette introduction, de nombreux travaux universitaires ont vu le jour portant sur l'impact, ou tout simplement l'effet contradictoire du processus révolutionnaire en Grande-Bretagne. L'ambition du numéro est de donner une vision étendue des recherches qui ont récemment réexaminé l'influence de la Révolution française dans les îles britanniques et les réactions de la Grande-Bretagne à la "révolution de France ». Certains lecteurs regretteront le manque de place laissé à l'histoire économique et sociale. Mais, ce numéro se voulant un instantané, force est de constater que, du côté britannique, la vitalité des travaux sur la culture politique l'emporte sur l'intérêt porté aux études d'histoire économique et sociale.

2 Résumer l'ensemble de ces communications serait un exercice vain! Nous retiendrons cependant un élément qui peut apparaître comme un lieu commun, mais est toutefois nécessaire de souligner : les répercussions exceptionnelles de la Révolution française à l'étranger. Rares sont les événements historiques qui ont pu susciter autant de réponses contradictoires; ainsi, Matthew 0 . Grenby met bien en valeur la profusion des réponses littéraires et des changements d'attitudes que la Révolution française a 
suscités. Plusieurs articles, fondés sur une prise en considération fidèle de l'historiographie récente, nourrissent des perspectives semblables et concluent de manière identique (Pierre-Yves Beaurepaire, Harry T. Dickinson, Charles John Fedorak, Emma Vincent Macleod, Mike Rapport, Atle Wold). D'autres encore, nous renseignent sur les liens idéologiques, encore obscurs, qui pouvaient exister entre les radicaux britanniques et les révolutionnaires français et mettent en valeur un choix rhétorique et référentiel proche (Fabrice Bensimon, Michael Davis, Rachel Hammersley). Mais plus que des antagonismes, que l'on a eu peut être tendance à sur-évaluer, ce numéro évoque avant tout les échanges réciproques entre deux nations confrontées à des choix essentiels - souvent dans l'incompréhension et la violence de la guerre -, formulés dans des configurations très différentes. L'histoire qui se noue entre 1789 et 1815 allait façonner les deux pays et les faire pénétrer dans le dix-neuvième siècle par des voies différentes qui, sans être aussi opposées qu'on le pense généralement, les engageaient définitivement dans des modèles de développement dont ils incarneront la figure symbolique, même si, à l'occasion, ils essayeront, l'un et l'autre, d'échapper à la fatalité de cette apparente détermination. Dans cette évolution, la Révolution française - puis l'Empire - ont joué, de l'autre côté de la Manche, un rôle de catalyseur de haines, mais également d'espoir, voire d'inspiration. Du côté français, pendant toute la période, la référence à la Grande-Bretagne sera également constante, devenant un objet à imiter, mais tenant lui aussi du repoussoir. La «culture politique » de ce temps, marquée par les confrontations et la fascination entre la France et l'Angleterre - alors que les populations bordières de la Manche continuaient de commercer ${ }^{1}$-, nous est ici rendue plus familière ${ }^{2}$.

\section{NOTES}

1.En complément de ce numéro spécial, le $n^{\circ}$ 1-2006 de la revue publiera deux notices bibliographiques (par J.M.A. Inglis et M. Czisnik) et une présentation de la thèse de Renaud Morieux (La Manche au 18e siècle. La construction d'une frontière franco-anglaise). 2.Nous tenons à remercier les auteurs du numéro, ainsi que les traducteurs : Renaud Morieux (articles de R. Hammersley, M. Rapport, E. Vincent Macleod, M. Davis), Lucie Perrier (M. O. Grenby, A. Wold, C.J. Fedorak), Pascal Dupuy (H.T. Dickinson). 